\title{
CD40/CD40 LIGAND INTERACTIONS AND TNFa TREATMENT REDUCE ACTIVITY OF P105 PROMOTER OF THE HUMAN PAPILLOMA VIRUS-18 IN VITRO
}

\author{
A. Altenburg ${ }^{1, *}$, M.B. Abdel-Naser, ${ }^{1,2}$, G. Nikolakis ${ }^{1}$, T. Wild ${ }^{1}$, N. Wojtalewicz ${ }^{1,3}$ \\ ${ }^{1}$ Department of Dermatology, Venereology, Allergology and Immunology, Dessau Medical Center, \\ Dessau D-06847, Germany \\ ${ }^{2}$ Department of Dermatology, Ain Shams University, Cairo 11566, Egypt \\ ${ }^{3}$ Center of Life Sciences Institute of Bioanalytical Sciences (IBAS), Anhalt University of Applied Sciences, \\ Bernburg D-06406, Germany
}

Background: Cervical carcinoma cells including those infected with the oncogenic human papilloma virus (HPV) and several cervical carcinoma cell lines show a strong expression of the CD40 receptor, unlike benign cervical epithelial cells infected with HPV. The functional relevance of this up-regulated expression in the tumor is not fully understood. Nevertheless, it might offer a unique possibility to target those malignant cells due to the antiviral and antitumoral effects of the CD40/CD40 ligand (CD40L) interactions. Aim: In vitro assessment of the effect of CD40L on HPV 18-P105 promoter activity and the subsequent release of IL-6 by the promoter transfected HeLa ${ }_{\mathrm{CD} 40}$ cells, which express CD40 constitutively. Material and Methods: Transfection of $\mathrm{HeLa}_{\mathrm{CD} 40}$ cells was achieved by electroporation after optimizing the parameters by the pCMV- $\beta$-Gal vector and $\beta-\mathrm{Gal}$ stain. Transfected $\mathrm{HeLa}_{\mathrm{CD} 40}$ cells were challenged with $\mathrm{BHK}_{\mathrm{CD} 40 \mathrm{~L}}$ and $\mathrm{TNF} \alpha$, in addition to $\mathrm{BHK}_{\mathrm{wt}}$ and medium alone as controls. $\mathrm{HPV18-}$ P105 promoter activity was demonstrated by luciferase reporter gene assay while IL-6 was assessed by ELISA. Results: CD40/ CD40L interactions and TNF $\alpha$ treatment significantly reduced HPV18-P105 promoter activity $(56.0 \pm 10.2 \%$ and $64.1 \pm 9.1 \%$ vs. control, respectively; $\mathrm{p}<\mathbf{0 . 0 0 1}$ ). Likewise, IL-6, which is a sensitive cytokine of CD40 activation, was significantly increased in $\mathrm{HeLa}_{\mathrm{CD} 40}$ cells in the same experiments (2.7 fold after stimulation with $\mathrm{BHK}_{\mathrm{CD} 40 \mathrm{~L}}$ and 5.2 fold after stimulation with $\mathrm{TNF} \alpha$ vs. control; $p<0.01$ and $p<0.001$, respectively). Conclusion: It is likely that the CD40/CD40L interactions and TNF $\alpha$ are effective against cervical carcinomas by repressing transcriptional activity of HPV promoter. This can result in new adjuvant treatments. Key Words: human papilloma virus, CD40, CD40 ligand, promoter, repression.

\section{INTRODUCTION}

CD40 is a member of the TNFR family. It is expressed on B cells, monocytes, dendritic cells, and a variety of nonhemopoietic cells, including normal keratinocytes, tumor cells, and many in vitro transformed and carcinoma-derived cell lines. CD40L, a member of the TNF superfamily, is expressed primarily by activated $T$ cells, activated $B$ cells and platelets and under inflammatory conditions on monocytic cells, natural killer cells and mast cells. CD40/CD40L engagement is required for $\mathrm{B}$-cell differentiation, isotype switching, maturation of dendritic cells and subsequent stimulation of antigen-specific T cells [1].

The CD40/CD40L interactions in tumor cells seem to be pleiotropic and context dependent as it may not only inhibit tumor growth via immunologic mechanisms and induction of apoptosis but also may stimulate tumor growth via various cytokines and growth factors including IL-6 and VEGF, among others [2]. Likewise, TNFa exerts selective direct tumor cytotoxicity but also promotes tumor development and metastases

Submitted: May 26, 2015.

${ }^{\star}$ Correspondence: E-mail: andreas.altenburg@klinikum-dessau.de Abbreviations used: BHK - baby hamster kidney; CD40L CD40 ligand; HPV - human papilloma virus; IL-6 - interleukin-6; IL-18 - interleukin-18; LCR - long control region; RLU - relative light units; SN - supernatant; STAT3 - signal transducer and activator of transcription 3; TNF - tumor necrosis factor; VEGF - vascular endothelial growth factor. via NO release and angiogenesis [3]. In vivo and in vitro studies revealed that oncogenic human papilloma viruses (HPV) positive cervical carcinoma and HPV positive cervical carcinoma cell lines expressed CD40 at the high levels, in contrast to normal cervical epithelium and non-malignant keratinocyte cell lines transfected with HPV-DNA [4, 5]. This discrepancy may provide an explanation for persistence of HPV infection by evading the immune system as shown by increased production of IL-18 binding protein that antagonizes the inflammatory cytokine IL-18 and attenuates the response to CD40 ligation and the capacity to attract peripheral blood mononuclear cells [6, 7]. This immune escape may be the rational for the poor prognosis of cervical carcinoma in the presence of HPV-18 genotype [8]. The selective effect of TNFa on HPV infection is not known but previous studies have shown that both CD40/CD40L interactions in the presence of a protein inhibitor and TNFa exerted a direct $\mathrm{HeLa}_{\mathrm{CD} 40}$ cytotoxicity, however it is unclear whether this effect also affects HeLa ${ }_{\mathrm{CD} 40}$ cells' HPV infection [9].

The aim of the present work is to examine the functional consequences of CD40/CD40L interactions and TNFa treatment on the HPV-18-p105 promoter activity of transfected $\mathrm{HeLa}_{\mathrm{CD} 40}$ cells in vitro.

\section{MATERIALS AND METHODS}

Cell lines and formaldehyde fixation. The cervical carcinoma cell line HeLa $\mathrm{CD}_{\mathrm{C} 0}$ (for cloning of CD40cDNA and transfection see [10], CCL 2; American 
Type Culture Collection, Kockville, MD) and the baby hamster kidney $\left(\mathrm{BHK}_{\mathrm{CD} 40 \mathrm{~L}}\right)$ cells, transfected with CD40L CDNA [11] (ACC 61; German Collection of Micro-organisms and Cell Cultures, Braunschweig, Germany) were cultured in DMEM supplemented with $10 \%$ heat-inactivated fetal calf serum, $1 \mathrm{mM}$ sodium pyruvate, $2 \mathrm{mM}$ L-alanyl-L-glutamine and antibiotics (all from Life Technologies, Eggenstein, Germany). Formaldehyde-fixed $\mathrm{BHK}_{\mathrm{CD} 40 \mathrm{~L}}$ cells and the wild type variant $\mathrm{BHK}_{\mathrm{wt}}$ were prepared as described previously [9]. Formaldehyde fixation of BHK cells prevents cellular adhesion to culture plates and release of autologous cytokines in an appreciable amount.

Transient transfection and assays. 1. Optimization of transfection efficiency by electroporation. The $\mathrm{pCMV}-\beta-$-Gal vectors and $\beta$-Gal stain method were used for adjustment and optimization of the electroporation variable parameters as previously described (Fig. 1, a) [12]. The voltage was varied at a range of 220 to $350 \mathrm{~V}$ with stepwise increments of $10 \mathrm{~V}$, while the capacitance was tested at a range of 900 to $1400 \mu \mathrm{F}$ with stepwise increments of $150 \mu \mathrm{F}$. The optimal parameters were found to be $300 \mathrm{~V} / 1050 \mu \mathrm{F}$ as demonstrated by the count and the density of the deep blue color of the transfected cells (Fig. 1, b, c). 2. Reporter gene assays (Luciferase assay). The luciferase expression test represents a reporter system for analysis of regulatory DNA sequence in which luciferase catalyzes the D-luciferin to emit a green luminescence that can be quantitatively measured. Electroporation cuvettes, each containing $0.8 \mathrm{ml}$ of $\mathrm{HeLa}_{\mathrm{CD} 40}$ cell suspension (adjusted at ca. $8-9 \cdot 10^{6} \mathrm{cells} / \mathrm{ml}$ ), to which $10 \mu \mathrm{g} \mathrm{4321-luc} \mathrm{DNA}$ (the entire HPV18 long control region (LCR) and the p105 promoter are conjugated on the luciferase gene) (Dr. Steger, Cologne, Germany) or $10 \mu \mathrm{g}$ pCMV- $\beta$-Gal vector that served as a control were added. Mixtures were left at room temperature for $10 \mathrm{~min}$ and followed by application of the optimum electric pulses $(300 \mathrm{~V}$, $1050 \mu \mathrm{F}$ ). Cells of 10 cuvettes were collected, gently mixed and seeded at equal number in 20 culture plates for $24 \mathrm{~h}$ followed by addition of formaldehyde-fixed $\mathrm{BHK}_{\mathrm{CD} 40 \mathrm{~L}}$ (6 plates, $2 \cdot 10^{6} \mathrm{cells} /$ plate), formaldehydefixed $\mathrm{BHK}_{\mathrm{wt}}\left(6\right.$ plates, $2 \cdot 10^{6}$ cells/plate) and TNFa (4 plates, each contains $1000 \mathrm{U} / \mathrm{ml}$ ) while the remaining 4 plates contained medium only and served as controls. Culture plates were incubated at $37^{\circ} \mathrm{C}$ for $43 \mathrm{~h}$ followed by a gentle wash with warm medium to remove the BHK cells and TNFa. The transfected cells were washed with cold PBS and retrieved by a rubber scraper in $1.8 \mathrm{mI}$ PBS. After centrifugation $\left(250 \mathrm{~g}, 4^{\circ} \mathrm{C}, 7 \mathrm{~min}\right.$ ) cells were resuspended in $50 \mu \mathrm{l} \mathrm{ex}$ traction buffer, lysed by 4 freeze-thaw cycles (each for 2 min in liquid nitrogen at $-196^{\circ} \mathrm{C}$ and 2 min in water bath at $37^{\circ} \mathrm{C}$ ), and followed by ultracentrifugation $\left(1400 \mathrm{~g}, 5 \mathrm{~min}\right.$ at $\left.4{ }^{\circ} \mathrm{C}\right)$. The extract was retrieved and kept on ice. The luciferase activity was measured by mixing $15 \mu \mathrm{l}$ of the extract with $100 \mu \mathrm{l}$ of the luciferase assay buffer (containing rATP). After injection of $300 \mu$ l solvent $(0.356 \mathrm{mM}$ D-luciferin dissolved in luciferase buffer) the relative light units (RLU) were immediately measured in a LB 9501 luminometer (Berthold Technologies, Bad Wildbad, Germany). On the other hand, the control reaction consisted of $470 \mu \mathrm{l} \beta$-galactosidase-buffer, $100 \mu \mathrm{l}$ ONPG solution $(4 \mathrm{mg} / \mathrm{ml}$ O-Nitrophenol- $\beta$-D-galactosidase in $0.1 \mathrm{M} \mathrm{Na}_{2} \mathrm{HPO}_{4}$-buffer, $\mathrm{pH} 7$ ) and $30 \mu \mathrm{l}$ cell extract which were incubated till they attain yellow color. Wells with $\beta$-Gal buffer and ONPG only served as controls. After stopping the reaction with $250 \mu \mathrm{l} \mathrm{NaCO}$, the fluorescence was measured at a wave length of $420 \mathrm{~nm}$ (Fig. 1, a).

\begin{tabular}{|c|c|}
\hline \multicolumn{1}{|c|}{ HeLa $_{\mathrm{CD} 40}$} \\
\hline Optimization of transfection by electroporation with the plasmid \\
$\mathrm{pCMV}-\beta \mathrm{Gal}$ ( $\beta$-Gal stain)
\end{tabular}

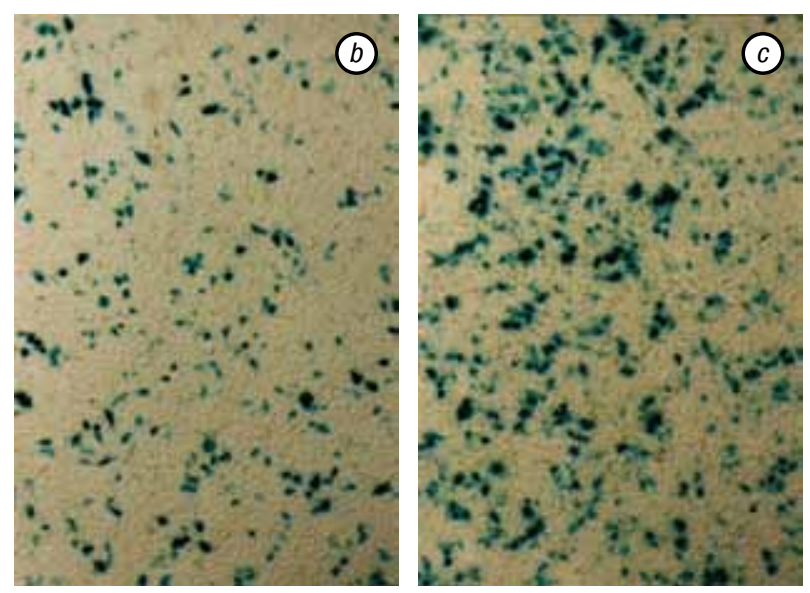

Fig. 1. Schematic representation of the experimental design, steps and methods $(a)$. Detection of $\beta$-galactosidase activity after electrotransfection of $\mathrm{HeLa}_{\mathrm{CD} 40}$ cells (with $\mathrm{pCMV}-\beta-\mathrm{Gal}$; original magnification, $\times 40 ; b-$ electroporation parameters $240 \mathrm{~V}$ and $1050 \mu \mathrm{F} ; c$ - electroporation parameters $300 \mathrm{~V}$ and $1050 \mu \mathrm{F}$; the latter represents the optimal parameters as shown by the count and density of the blue dye)

Assessment of IL-6 by ELISA. Cells were seeded in 24-well plates at a density of $1.5 \cdot 10^{5}$ cells/well and were challenged after $24 \mathrm{~h}$ with $\mathrm{BHK}_{\mathrm{CD} 40 \mathrm{~L}}$ cells, $\mathrm{BHK}_{\mathrm{wt}}$ cells (each with $2 \cdot 10^{6} \mathrm{BHK} /$ well), TNFa $(1000 \mathrm{U} / \mathrm{ml})$ or left with medium alone that served as a control. After $16 \mathrm{~h}$, supernatants (SNs) were collected, cellular debris was removed by centrifugation and the IL-6 contents were assessed by ELISA as previously described [11]. Briefly, Maxisorp plates (Nunc, Wiesbaden, Germany) were coated with $1 \mathrm{mg} / \mathrm{ml}$ antiIL-6 overnight. After blocking of the plates for $1 \mathrm{~h}$ with PBS containing 0.5\% BSA, 0.05\% Tween 20 (Serva, Heidelberg, Germany), and $0.02 \% \mathrm{NaN}_{3}$, SNs and serial dilutions of the recombinant human IL-6 (Tebu, Frankfurt, Germany) as standards were added for $6 \mathrm{~h}$. Plates were then incubated with polyclonal anti- 
IL-6 overnight (Tebu, Frankfurt, Germany) followed by a 2-hour incubation with peroxidase-labeled goat anti-rabbit $F(a b)$ after which the substrate was applied and the absorbance was measured with an ELISA reader (SLT Lab Instruments, Hannover) at $405 \mathrm{~nm}$ (Fig. 1, a).

Statistical analysis. The mean and standard deviation of values obtained from each assay were calculated and the percentage decrease of luciferase assays was estimated. Unpaired Student $t$ test was used to evaluate the difference between means and SD of reporter gene assay and IL-6.

\section{RESULTS}

CD40/CD40L interactions and TNFa treatment reduced the HPV18-P105-promoter activity in HeLa cells that expressed CD40 constitutively. To examine the possible regulatory effect of CD40L on the HPV18 control region, the HeLa $\mathrm{CD}_{40}$ cells transfected with reporter gene were stimulated for $43 \mathrm{~h}$ with formaldehyde-fixed $\mathrm{BHK}_{\mathrm{CD} 40 \mathrm{~L}}$ cells and also with TNFa. Formaldehyde-fixed $\mathrm{BHK}_{\mathrm{wt}}$ and medium alone served as controls. The activity of HPV18-P105promoter stimulated by formaldehyde-fixed $\mathrm{BHK}_{\mathrm{CD} 40 \mathrm{~L}}$ (RLU $2902.3 \pm 291.49$ vs. $4488 \pm 459.62 ; p=0.017$ ) (in the four experiments) was repressed by a mean of $56 \pm 10.2 \%$, in comparison with $\mathrm{BHK}_{\mathrm{wt}}$ (RLU $5114 \pm$ 917.32 vs. $4488 \pm 459.62 ; p=0.45)$. Similarly, they were significantly stimulated by $1000 \mathrm{U} / \mathrm{ml} \mathrm{TNFa} \mathrm{(RLU}$ $1765 \pm 321.02$ vs. $4488 \pm 459.62 ; p=0.02$ ). On the other hand, formaldehyde-fixed $\mathrm{BHK}_{\mathrm{wt}}$ induced no significant effect in comparison with control medium (RLU $5114 \pm 917.32$ vs. $4488 \pm 459.62 ; p=0.45$ ) (Fig. 2, a) . It has been shown earlier that TNFa negatively regulates the HPV16 gene expression [13]. In the present work, activity of the HPV18-P105-promoter was repressed by TNFa by a mean of $64.9 \pm 9.1 \%$ in comparison with medium. The standard deviations from several probes within each experiment were between 1.0 and $10.1 \%$. In contrast, the control pCMV- $\beta-G a l$ vector-transfected $\mathrm{HeLa}_{\mathrm{CD} 40}$ cells incubated with formaldehyde-fixed $\mathrm{BHK}_{\mathrm{CD} 40 \mathrm{~L}}$ or $\mathrm{BHK}_{\mathrm{wt}}$ cells or TNFa or medium alone showed similar and non-significant CMV promoter activity in all probes $(p>0.05)$.

CD40/CD40L interactions and TNFa treatment induce IL- 6 release by the HeLa ${ }_{\mathrm{CD} 40}$ cells transfected with HPV18-P105. As IL-6 represents a very sensitive parameter for activation of the CD40 and TNFa receptors, its concentration was determined upon stimulation. It was found that levels of IL-6 produced by $\mathrm{HeLa}_{\mathrm{CD} 40}$ cells increased significantly when challenged by both formaldehyde-fixed $\mathrm{BHK}_{\mathrm{CD} 40 \mathrm{~L}}$ and TNFa but not by formaldehyde-fixed $\mathrm{BHK}_{\mathrm{wt}}$. The increase of IL-6 was up to 2.7 fold with $\mathrm{BHK}_{\mathrm{CD} 40 \mathrm{~L}}(p<0.01)$ and 5.2 fold with TNFa $(p<0.001)$ after $16 \mathrm{~h}$ incubation with $\mathrm{HeLa}_{\mathrm{CD} 40}$ transfected with the HPV18-105 (Fig. 2, b). This illustrates the efficient stimulation with the functionally active CD40L and TNFa and also confirms the survival of the transfected $\mathrm{HeLa}_{\mathrm{CD} 40}$ cells and their sustained efficiency in releasing IL-6 upon stimulation.

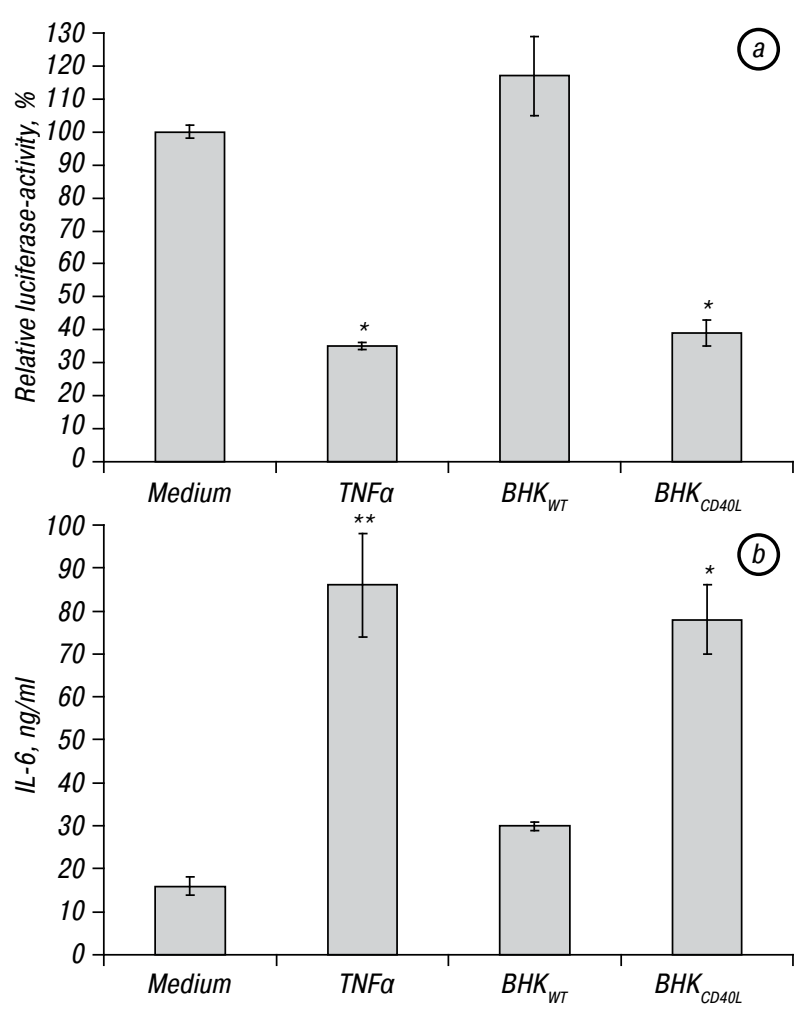

Fig. 2. Effect of CD4OL and TNFa on transcription activity of HPV-LCR: $a$ - transfected HeLa $\mathrm{CD} 40$ cells stimulated by TNFa and formaldehyde-fixed $\mathrm{BHK}$ cells for $43 \mathrm{~h}$ showed repression by $\mathrm{BHK}_{\mathrm{CD} 40 \mathrm{~L}}$ and TNFa but not $\mathrm{BHK}_{\mathrm{wt}}\left({ }^{*} p<0.01\right.$ vs. $\mathrm{BHK}_{\mathrm{wt}}$ and medium) as assessed by the luciferase activity; $b-$ IL- 6 was significantly elevated in the SNs of the corresponding experiment after $16 \mathrm{~h}$ incubation as assessed by ELISA $\left({ }^{*} p<0.01 v s\right.$. BHK $\mathrm{wt}_{\mathrm{wt}}$ and ${ }^{* \star} p<0.001$ vs. medium)

\section{DISCUSSION}

The functional relevance of the CD40/CD40L interactions in malignant tumors is variable and likely context dependent. It has been shown that CD40/CD40L interactions or up-regulation of CD40 correlated with poor prognosis in pancreatic ductal carcinoma [14] and non-small lung cancer [15], whereas CD40 ligation exerts antiproliferative effects and apoptosis induction in malignant ovarian tumors [16] and melanoma cell lines [17]. Previous studies also showed that not only TNFa but also the CD40/CD40L interactions exert a direct cytotoxicity of $\mathrm{HeLa}_{\mathrm{CD} 40}$ cells in the presence of a protein inhibitor [9].

In vivo studies revealed that CD40 expression correlated with HPV positivity and VEGF expression as well as microvessel density, which provides explanation for its high levels in cervical carcinoma and its absence in cervicitis and normal cervix [18]. Persistent HPV infection of the cervical epithelium may lead to progression from cervical dysplasia to cancer over years or decades. Resolution of epithelial HPV infection depends on complex interactions between the HPVinfected keratinocytes and both host cell-mediated and humoral responses [19, 20]. Repression of HPV oncogenes in HeLa cells resulted in the orderly restoration of dormant tumor suppressor pathways via mobilization of the p53 and Rb pathways to deliver growth inhibitory signals to the cells [21]. Interestingly, we could show that CD40/CD40L interactions and TNFa treatment resulted 
in repression of the HPV18-p105-promoter in transfected $\mathrm{HeLa}_{\mathrm{CD} 40}$. This mechanism could be effective in early stages of HPV18-infection and could also contribute to the regression of HPV18-associated high-grade squamous intraepithelial or tumor lesions expressing the HPV oncogene products. Accordingly, HPV-induced cancer therapeutic vaccines targeting the E6 and E7 oncoproteins are combined with adjuvant and costimulatory anti-CD40 antibodies. The CD40/CD40L interactions and TNFa treatment exert several antitumor effects, directly by cytotoxicity and indirectly via repression of oncogenes and eliciting antigen-specific $T$ cell responses [22].

Various cytokines have been implicated in the pathogenesis of cervical cancer, among which IL-6 has received particular attention. Similarly to CD40/CD40L interactions and TNFa treatment, IL- 6 shows a contextdependent pleiotropic effect as it promotes growth of certain tumors, such as cervical cancer, whereas it inhibits the growth of others. Recent studies showed that IL-6 favors proliferation and metastatic spread and its high expression in cervical malignant cells corresponds to bad prognosis. It has also been shown that IL-6 promotes cervical tumorigenesis mainly by activating VEGFmediated angiogenesis via a STAT3 pathway [23]. In the present study, decreased activity of HPV18-105 promoter upon $\mathrm{BHK}_{\mathrm{CD} 40 \mathrm{~L}}$ and TNFa treatment was associated with the significant increase of IL- 6 levels. Although, the released IL-6 may provide neovascularization, promoting tumor growth and spread; this may also result in efficient recruitment of immune cells and better delivery of therapeutic cytotoxic drugs. Furthermore, certain cytotoxic drugs, such as zerumbone, not only induce cell death and apoptosis but also inhibit IL-6 release [24].

To conclude, the present study further confirms the antitumor properties of CD40/CD40L interactions and TNFa treatment in HPV-positive cervical carcinoma. Boosting of CD40 expression and release of TNFa might be considered as adjuvant therapies.

\section{ACKNOWLEDGEMENTS}

The authors thank Prof. Herbert Pfister, Institute of Virology of the University of Cologne, for providing of laboratories and laboratory materials, and Dr. Gertrud Steger, Institute of Virology of the University of Cologne, for the plasmid 4321-luc.

\section{REFERENCES}

1. Elgueta R, Benson MJ, de Vries VC, et al. Molecular mechanism and function of CD40/CD40L engagement in the immune system. Immunol Rev 2009; 229: 152-72.

2. Bereznaya NM, Chekhun VF. Expression of CD40 and CD40L on tumor cells: the role of their interaction and new approach to immunotherapy. Exp Oncol 2007; 29: 2-12.

3. Balckwill F. Tumour necrosis factor and cancer. Nat Rev Cancer 2009; 9: 361-71.

4. Altenburg A, Baldus SE, Smola H, et al. CD40 ligandCD40 interaction induces chemokines in cervical carcinoma cells in synergism with IFN-gamma. J Immunol 1999; 162: 4140-7.

5. Hill SC, Youde SJ, Man S, et al. Activation of CD40 in cervical carcinoma cells facilitates CTL responses and augments chemotherapy-induced apoptosis. J Immunol 2005; 174: 41-50.
6. Richards KH, Doble R, Wasson CW, et al. Human papillomavirus $\mathrm{E} 7$ oncoprotein increases production of the antiinflammatory interleukin-18 binding protein in keratinocytes. J Virol 2014; 88: 4173-9.

7. Tummers B, Goedemans R, Jha V, et al. CD40-mediated amplification of local immunity by epithelial cells is impaired by HPV. J Invest Dermatol 2014; 134: 2918-27.

8. Gadducci A, Guerrieri ME, Greco C. Tissue biomarkers as prognostic variables of cervical cancer. Crit Rev Oncol Hematol 2013; 86: 104-29.

9. Hess S, Engelmann H. Anovel function of CD40: Induction of cell death in transformed cells. J Exp Med 1996; 183: 159-67.

10. Hess S, Kurrle R, Lauffer L, et al. A cytotoxic CD40/ p55 tumor necrosis factor receptor hybrid detects CD40 ligand on herpesvirus saimiri-transformed T cells. Eur J Immunol 1995; 25: $80-6$.

11. Hess S, Rensing-Ehl A, Schwabe R, et al. CD40 function in non-hematopoietic cells: mobilization of NF-kB and induction of IL-6 production. J Immunol 1995; 155: 4588-95.

12. Potter H, Heller R. Transfection by electroporation. Curr Protoc Mol Biol 2010; Chapter 9: Unit 9.3. doi: 10.1002/0471142727.mb0903s92.

13. Kyo $S$, Inoue $M$, Hayasaka $N$, et al. Regulation of early gene expression of human papillomavirus type 16 by inflammatory cytokines. Virology 1994; 200: 130-9.

14. Shoji $Y$, Miyamoto $M$, Ishikawa $K$, et al. The CD40CD154 interaction would correlate with proliferation and immune escape in pancreatic ductal adenocarcinoma. J Surg Oncol 2011; 103: $230-8$.

15. Ishikawa K, Miyamoto M, Yoshioka T, et al. Upregulation of CD40 with juxtacrine activity in human nonsmall lung cancer cells correlates with poor prognosis. Cancer 2008; 113: $530-41$.

16. Toutirais O, Gervais A, Cabillic F, et al. Effects of CD40 binding on ovarian carcinoma cell growth and cytokine production in vitro. Clin Exp Immunol 2007; 149: 372-5.

17. Von Leoprechting A, van der Bruggen $\mathrm{P}$, Pahl HL, et al. Stimulation of CD40 on immunogenic human malignant melanomas augments their cytotoxic T lymphocyte-mediated lysis and induces apoptosis. Cancer Res 1999; 59: 1287-94.

18. Huang Q, Qu QX, Xie F, et al. CD40 is overexpressed by HPV16/18-E6 positive cervical carcinoma and correlated with clinical parameters and vascular density. Cancer Epidemiol 2011; 35: 388-92.

19. Abdel-Naser MB, Wollina U, Habib MA, et al. Nonsarcoidal, non-tuberculoid granuloma in common variable immunodeficiency. J Drugs Dermatol 2006; 5: 272-6.

20. Evans EM, Man S, Evans AS, et al. Infiltration of cervical cancer tissue with human papillomavirus-specific cytotoxic T-lymphocytes. Cancer Res 1997; 57: 2943-50.

21. Goodwin EC, DiMaio D. Repression of human papillomavirus oncogenes in HeLa cervical carcinoma cells causes the orderly reactivation of dormant tumor suppressor pathways. Proc Natl Acad Sci U S A 2000; 97: 12513-8.

22. Barrios K, Celis E. TriVax-HPV: an improved peptidebased therapeutic vaccination strategy against human papillomavirus-induced cancers. Cancer Immunol Immunother 2012; 61: 1307-17.

23. Wei LH, Kuo ML, Chen CA, et al. Interleukin-6 promotes cervical tumor growth by VEGF-dependent angiogenesis via a STAT3 pathway. Oncogene 2003; 22: 1517-27.

24. Abdelwahab SI, Abdul AB, Zain ZN, Hadi AH. Zerumbone inhibits interleukin- 6 and induces apoptosis and cell cycle arrest in ovarian and cervical cancer cells. Int Immunopharmacol 2012; 12: 594-602. 